\title{
Epidemiology of Cleft Lip and Palate among Infants Born in Chandigarh
}

\author{
Dara Singh $^{1}$, Satinder P Singh ${ }^{2}$, Ashok Utreja $^{3}$, Ashok Jena ${ }^{4}$, Sanjeev Verma ${ }^{5}$, Raj K Verma ${ }^{6}$
}

\begin{abstract}
Aim and objective:To determine the incidence of cleft deformity in Chandigarh by monitoring the total live births occurring at different birth facilities. Materials and methods: This cross-sectional study was carried out at all birth facilities of UT, Chandigarh during the period between 1 st January 2009 and 31st December 2010. Total 35 birth facilities, 6 government hospitals, and 29 private nursing homes were included in the study. This epidemiological study was based on monitoring of all the live births and recorded the incidence of type of cleft deformity, associated congenital malformations, birth order, family history, detection, and diagnosis with ultrasonography and folic acid intake during pregnancy.

Results: Forty eight babies with different types of cleft deformities were born with an incidence of $0.97 / 1,000$ live births. Group- 1 , group- 1 (A), group- 2, and group- 3 (as per Balakrishnan classification) and miscellaneous group included eight (16.66\%), 10 (20.84\%), 13 (27.08\%), 14 (29.16\%) newborns, and three (6.26\%) newborns (one with subcutaneous cleft and palate while two with midline cleft deformity of face), respectively. The frequency of cleft deformity was significantly more among males except isolated cleft palate group which showed equal distribution. About $15(46.87 \%)$ newborns had cleft deformity on left side, 10 (31.25\%) on right side while seven $(21.87 \%)$ had bilateral cleft deformity. The overall percentage of subjects of cleft with associated major anomalies or syndromes was $22 \%$.

Conclusion: The incidence of cleft deformity in Chandigarh region was found to be $0.97 / 1,000$ live births. The frequency of cleft deformity was more among males as compared to females except isolated cleft palate group which showed equal distribution. The laterality of the cleft deformity was more on left side followed by right side and then bilateral. Improved training to radiologists and gynecologists could increase the detection rates of orofacial clefts during pregnancy.

Keywords: Cleft lip and palate, Epidemiology, Incidence.

Journal of Postgraduate Medicine, Education and Research (2022): 10.5005/jp-journals-10028-1550
\end{abstract}

\section{InTRODUCTION}

Cleft lip and/or palate is one of the most common congenital malformations of the head and neck region. ${ }^{1,2}$ Orofacial clefts (OFCs) are usually associated with esthetic and functional problems that include difficulty in feeding, dental problems, abnormal facial growth, speech development, and hearing difficulties. The etiology of orofacial clefts is generally thought to be multifactorial involving both genetic and environmental factors. ${ }^{3}$ These clefts occur in individuals of all socioeconomic and ethnic backgrounds. The birth prevalence of orofacial clefts in different populations around the globe is in the range of $0.6-4.9$ per 1,000 patients. ${ }^{4-17}$ Comparison of figures for birth prevalence is complicated by the different methodologies used to determine birth prevalence as some studies used only live births $s^{5,8}$ and others included live births, stillbirths, and abortions. The incidence of cleft deformity in various regions in India was reported in the range of $0.54-2.75$ per 1,000 live births. ${ }^{18-32}$ Most of the Indian data comes from relatively small, local hospital-based studies and included stillbirths in recording the prevalence of birth defects of oral clefts. ${ }^{18}$ An earlier study conducted in Chandigarh by Saifullah et al. ${ }^{19}$ in a single birth facility on 1,000 consecutive births found one newborn with cleft lip and palate deformity with incidence of $1 / 1,000$ births. In majority of the studies, the data on incidence is mostly based on hospital related figures and may not be a true representation of the actual occurrence of the birth defects related to clefts. ${ }^{18-28}$

The feeding, aesthetics, dento-facial, and psychosocial problems in patients with cleft lip and palate need to be addressed extensively. Counseling and guidance to the parents of
${ }^{1}$ Department of Orthodontics, Eklavya Dental College, Kotputli, Rajasthan, India

2,5,6 Unit Of Orthodontics, Oral Health Sciences Centre, Postgraduate Institute of Medical Education and Research, Chandigarh, India

${ }^{3}$ Oral Health Sciences Centre, Postgraduate Institute of Medical Education and Research, Chandigarh, India

${ }^{4}$ Department of Dentistry, All India Institute of Medical Sciences, Bhubaneswar, Orissa, India

Corresponding Author: Satinder P Singh, Unit of Orthodontics, Oral Health Sciences Centre, Postgraduate Institute of Medical Education and Research, Chandigarh, India, Phone: +91 9815933748, e-mail: drspsingh_chd@yahoo.com

How to cite this article: Singh D, Singh SP, Utreja A, et al. Epidemiology of Cleft Lip and Palate among Infants Born in Chandigarh. J Postgrad Med Edu Res 2022;56(1):13-20.

Source of support: Nil

Conflict of interest: None

children born also require consideration for future treatment and comprehensive management of the defect and its related problems. Thus, it is important to conduct an epidemiological survey to investigate the incidence of cleft deformity in Chandigarh to predict the total burden of care and improve planning of health related services for the management of cleft deformity. Hence, the present study was planned with the objective to determine the incidence of cleft deformity in Chandigarh by monitoring the total live births occurring at different birth facilities over a period of 24 months.

(c) The Author(s). 2022 Open Access This article is distributed under the terms of the Creative Commons Attribution 4.0 International License (https://creativecommons. org/licenses/by-nc/4.0/), which permits unrestricted use, distribution, and non-commercial reproduction in any medium, provided you give appropriate credit to the original author(s) and the source, provide a link to the Creative Commons license, and indicate if changes were made. The Creative Commons Public Domain Dedication waiver (http://creativecommons.org/publicdomain/zero/1.0/) applies to the data made available in this article, unless otherwise stated. 


\section{Materials and Methods}

This cross-sectional study was carried out at all birth facilities of UT, Chandigarh during the period between 1st January 2009 and 31st December 2010. Chandigarh (UT), the capital city of Punjab and Haryana, provides health facilities which are well planned and birth registration is centralized. All the births and deaths in Chandigarh are registered at Birth and Death Registration Department, Chandigarh administration (Sector-17, Chandigarh UT). Thus, it provides an optimum facility for conducting an epidemiological study specifically related to births and deaths. All the concerned authorities responsible for the birth and neo-natal care in Chandigarh city were explained the aim and objectives of study and were regularly visited by the investigator. Permission from the concerned authorities of all birth facilities was obtained before conducting this study. This study relied on data obtained from Neonatal Units at Departments of Gynaecology and Obstetrics from all birth facilities in Chandigarh. The list of all birth facilities in Chandigarh was collected from Birth and Death Registration Department (Sector-17, Chandigarh). Total 35 birth facilities, 6 government hospitals, and 29 private nursing homes were included in the study. This epidemiological study was based on monitoring of all the live births and recording the data related to newborns with cleft deformities. All the live newborns with the cleft deformity were recorded in the study during the above period. Before starting the study during the visits to the birth facilities, it was noticed that most parents of the newborn babies with cleft deformity were unaware on various aspects of this deformity like feeding method, treatment aspects and the overall management of babies with cleft deformity. Considering this, Information Education and Communication (IEC) Brochures were prepared for distribution to the parents in three languages (Hindi, English, and Punjabi) and they were distributed among doctors, nurses, and patients for general information regarding this congenital deformity. This brochure included description of cleft deformity, possible risk factors of cleft deformity, feeding problems, chances of ear infection and hearing loss, speech and language problems, dental problems, aesthetic and function problems, counseling regarding feeding technique, psychological aspects, regarding primary and secondary surgery, prevention of cleft deformity, and timing for different surgical and nonsurgical treatment protocol as per PGIMER guidelines.

Collection of data: Data collection was started from 1st January 2009. After getting telephonic information on birth of newborn with the cleft deformity from the birth facility or during weekly visit by the investigator to the birth facility, investigator visited the parents of newborns. The immediate concern about feeding the baby was addressed and counseling provided for different methods to feed the babies with cleft deformity. Along with interview, the parents were informed about all the treatment modalities and were guided for free surgical treatment at Post Graduate Institute of Medical Education and Research, a Smile Train partner. They were subsequently counseled and guided regarding the general health of the newborn, the severity of the cleft, speech, and growth of the orofacial region. The need for general dental awareness and the optimum orthodontic care for rehabilitation of the child with cleft were also explained.

The type of cleft and any associated deformity, any history of past abortions, presence of cleft in the family and other demographic data with regard to the parents of the newborn with cleft deformity were recorded on a standard Proforma. Along with cleft deformity, other congenital malformations were also recorded in the Proforma, as observed and recorded by the attending pediatrician. The type of cleft deformity was recorded as per the classification given by C. Balakrishnan. ${ }^{33}$ However, some rare clefts like oro-ocular, oro-auricular, midline facial cleft, subcutaneous cleft etc. were included in a separate miscellaneous group. Apart from recording the problems on a standard Proforma, facial photograph of each newborn with cleft deformity was also recorded by a digital camera for the validation of type of cleft deformity. Some newborns with cleft lip and palate who could not be recorded at primary birth facilities or who were born at home got recorded later when they reported to the tertiary healthcare center for surgery.

\section{Statistical Analysis}

The statistical analysis was carried out using Statistical Package for Social Sciences (SPSS Inc., Chicago, IL, version 15.0 for Windows). All quantitative variables were estimated using measures of central location (mean, median), measures of dispersion (standard deviation and standard error), and IQR. Qualitative or categorical variables were described as frequencies and proportions. Proportions were compared using Chi-square or Fisher's exact test whichever was applicable. All statistical tests were two-sided and performed at a significance level of 0.05 .

\section{Results}

A total of 48 babies with various types of cleft deformities were born in the city during the study period of 24 months. Total live births in Chandigarh city according data obtained from Birth registration office during the same period were 49,215. The incidence of cleft deformity was found to be as $0.97 / 1,000$ live births. The distribution of various types of orofacial clefts is shown in Table 1. Among 48 newborns with cleft deformity, group- 1, group-1(A), group-2 and group- 3 included eight (16.66\%), 10 (20.84\%), 13 (27.08\%), and $14(29.16 \%)$ newborns, respectively while three (6.26\%) newborns, one $(2.08 \%)$ newborn with subcutaneous cleft and palate while two $(4.18 \%)$ with midline cleft deformity of face were included in miscellaneous group.

A total of 32 newborns, were classified according to the laterality of the clefts. Fifteen (46.87\%) newborns had cleft deformity on left side, 10 (31.25\%) on right side while seven (21.87\%) had bilateral cleft deformity. Among 48 newborns with various cleft deformities, 33 (68.75\%) were males and 15 (31.25\%) were females. The frequency of cleft deformity was more among males as compared to females and the difference was statistically significant (Chi-square test $=4.51$, $p$ value- 0.033 ). All types of cleft were found more frequently in males than in females except group- 3 which was equally distributed in both the genders.

The distribution of the cleft according to the gender and sides (left and right) among different groups is shown in Table 1. Eight newborns had cleft lip deformity (group-1) were all males. Of eight newborns, four (50\%) newborns had cleft deformities on left side and three (37.5\%) on right side and one (12.5\%) was a bilateral cleft. Ten newborns had cleft lip and alveolus deformity [group- 1(A)], which included eight (80\%) males and two (20\%) females. Out of eight males, four (50\%) newborns had cleft deformities on left side and three (37.5\%) on right side and only one (12.5\%) newborn had bilateral cleft. Among two female newborns with group- 1 (A) cleft deformity, one had cleft deformity on right side and one on left side. Thirteen newborns had isolated cleft palate deformity (group-2) and of these 13, eight (61.54\%) were males and five 
Epidemiology of Cleft Lip and Palate among Infants

Table 1: Distribution of newborns with various cleft deformities and their laterality

\begin{tabular}{|c|c|c|c|c|}
\hline & \multicolumn{2}{|c|}{ Malen } & Female $n$ & Total $n$ \\
\hline Number of total live births & \multicolumn{2}{|c|}{$26,312(53.4 \%)$} & $22,903(46.5 \%)$ & $49,215(100 \%)$ \\
\hline Number of newborns with cleft deformity & \multicolumn{2}{|c|}{$33(68.7 \%)$} & $15(31.3 \%)$ & $48(100 \%)$ \\
\hline Incidence of cleft deformity & \multicolumn{2}{|c|}{$1.25 / 1000$} & $0.65 / 1000$ & $0.97 / 1000$ \\
\hline \multicolumn{5}{|l|}{ Acc. to laterality $(n=32)$} \\
\hline \multirow[t]{2}{*}{ Unilateral } & Right & $7(22 \%)$ & $3(9.2 \%)$ & $10(31.2 \%)$ \\
\hline & Left & $11(34.3 \%)$ & $4(12.5 \%)$ & $15(46.8 \%)$ \\
\hline Bilateral & & $5(15.7 \%)$ & $2(6.3 \%)$ & $7(22 \%)$ \\
\hline Total & & $23(71.8 \%)$ & $9(28.2 \%)$ & $32(100 \%)$ \\
\hline \multicolumn{5}{|l|}{ Distribution according to cleft type } \\
\hline & & & & Total \\
\hline \multirow[t]{2}{*}{ Group- 1 (Unilateral) } & Right & $3(6.3 \%)$ & 0 & \\
\hline & Left & $4(8.3 \%)$ & 0 & $8(16.7 \%)$ \\
\hline Group- 1 (Bilateral) & & $1(2.1 \%)$ & 0 & \\
\hline \multirow[t]{2}{*}{ Group- 1(A) (Unilateral) } & Right & $3(6.3 \%)$ & $1(2.1 \%)$ & \\
\hline & Left & $4(8.3 \%)$ & $1(2.1 \%)$ & $10(20.8 \%)$ \\
\hline Group- 1(A) (Bilateral) & & $1(2.1 \%)$ & 0 & \\
\hline Group- 2 & \multicolumn{2}{|c|}{$8(16.7 \%)$} & $5(10.4 \%)$ & $13(27 \%)$ \\
\hline \multirow[t]{2}{*}{ Group- 3 (Unilateral) } & Right & $1(2.1 \%)$ & $2(4.2 \%)$ & \\
\hline & Left & $3(6.3 \%)$ & $3(6.3 \%)$ & $14(29.1 \%)$ \\
\hline Group- 3 (Bilateral) & & $3(6.3 \%)$ & $2(4.2 \%)$ & \\
\hline Miscellaneous (Rare clefts) & \multicolumn{2}{|c|}{$2(4.2 \%)$} & $1(2.1 \%)$ & $3(6.3 \%)$ \\
\hline Total & \multicolumn{2}{|c|}{33 (68.7\%) } & $15(31.3 \%)$ & $48(100 \%)$ \\
\hline
\end{tabular}

Comparison cleft deformity (Male to Female): Chi-square test $=4.51, p$ value- 0.033

Group- 2: odds ratio of males-0.64, and odds ratio of females: 1.56

Group- 3: odds ratio of males-0.31, and odds ratio of females: 3.25

Group-1- Isolated cleft lip, group-1(A)-Cleft lip and alveolus, group-2- Isolated cleft palate, group-3- Cleft lip, alveolus and palate

(38.46\%) were females. The male to female ratio was 1.6:1. Isolated cleft palate deformity was found more in males as compared to females but the frequency of having this deformity in female was more as compared to males as shown in odds ratio (odds ratio of males: 0.64 , and odds ratio of females: 1.56 ). The cleft lip, alveolus and palate deformity (group-3) was equally distributed among males and females as seven (50\%) newborns were males and seven (50\%) females. However, according to the odds ratio the deformity was more frequent among females (Odds ratio of males: 0.31 , odds ratio of females: 3.25 ).

A complete history of proper birth order could be obtained for 45 , out of 48 newborns with cleft deformity and the distribution of all newborns with cleft deformity according to their birth order, heredity, maternal intake of folic acid during pregnancy, detection of cleft deformity in ultrasonography during intrauterine life and associated with any other systemic abnormalities are shown in Tables 2 and 3.

\section{Discussion}

A total of 49,215 babies were born in Chandigarh UT during the study period of 24 months, out of which 48 babies had cleft deformity. In the present study, the incidence of cleft deformity in Chandigarh was 0.97 per 1,000 live births which is within range of $0.54-2.75$ per 1,000 live births, incidence of cleft deformity in previous studies conducted in various parts of India. ${ }^{18-32}$ The incidence of cleft deformity in Caucasian populations varied from $0.6-1.89$ per 1,000 births, the mean incidence being approximately 1 per 1,000 births and was similar to the present study conducted among Caucasians. ${ }^{7,8,34-41}$ The reported incidence of cleft lip, cleft palate, and cleft lip and palate for American Indians however ranged from $0.79-3.74$ per 1,000 live births. ${ }^{42-44,47}$ Black and Arab populations of the Middle East had a lower incidence of cleft deformity than Caucasians. ${ }^{45-49}$ Japanese have a higher incidence compared with the incidence of (Cleft lip and/or palate) $\mathrm{CL} \pm \mathrm{P}$ in Japanese of other parts of the world..$^{50,51}$

Most of the investigators around the world collected data from the hospital records. Saxen and Lahti ${ }^{52}$ in Finland, Will and Parsons ${ }^{53}$ in Illinois and Murray et al., ${ }^{54}$ Taher et al. ${ }^{55}$ in Tehran, Menegotto et al. ${ }^{56}$ in South America, Al Omari and Al-Omari ${ }^{57}$ in Jordon and Druschel et al. ${ }^{58}$ in the New York State, Vallino-Napoli et al. ${ }^{59}$ in Victoria, Australia, Gregg et al. ${ }^{60}$ in Northern Ireland, Fels Elliott et al. ${ }^{61}$ in Zambia, and Coupland and Coupland ${ }^{13}$ in United Kingdom reported the incidence and prevalence from either hospital based survey or records of the hospitals visiting for surgery.

\section{Distribution of Cleft Deformities}

In the present study, CL comprised of $37.5 \%$ of total orofacial cleft deformities similar to studies conducted by Rajabian et al. ${ }^{14}$ in Iran (34.9\%) and Jensen et al. ${ }^{8}$ in Denmark (33.5\%) whereas in few studies the distribution of cleft lip among all other types of clefts was reported to be higher. ${ }^{45,47,60,62,63}$ Mestrovic et al. ${ }^{16}$ in Croatia (17.2\%), Will and parsons ${ }^{52}$ in Illinois (8.33\%), and Aljohar et al. ${ }^{64}$ in Saudi Arabia (15.1\%) reported very low frequency of cleft lip among all types 
Epidemiology of Cleft Lip and Palate among Infants

Table 2: Distribution of newborns with various cleft deformities according to heredity, intake of folic acid by mother at various stages of pregnancy, detection of cleft deformity in ultrasonography during pregnancy, associated with any other systemic abnormalities

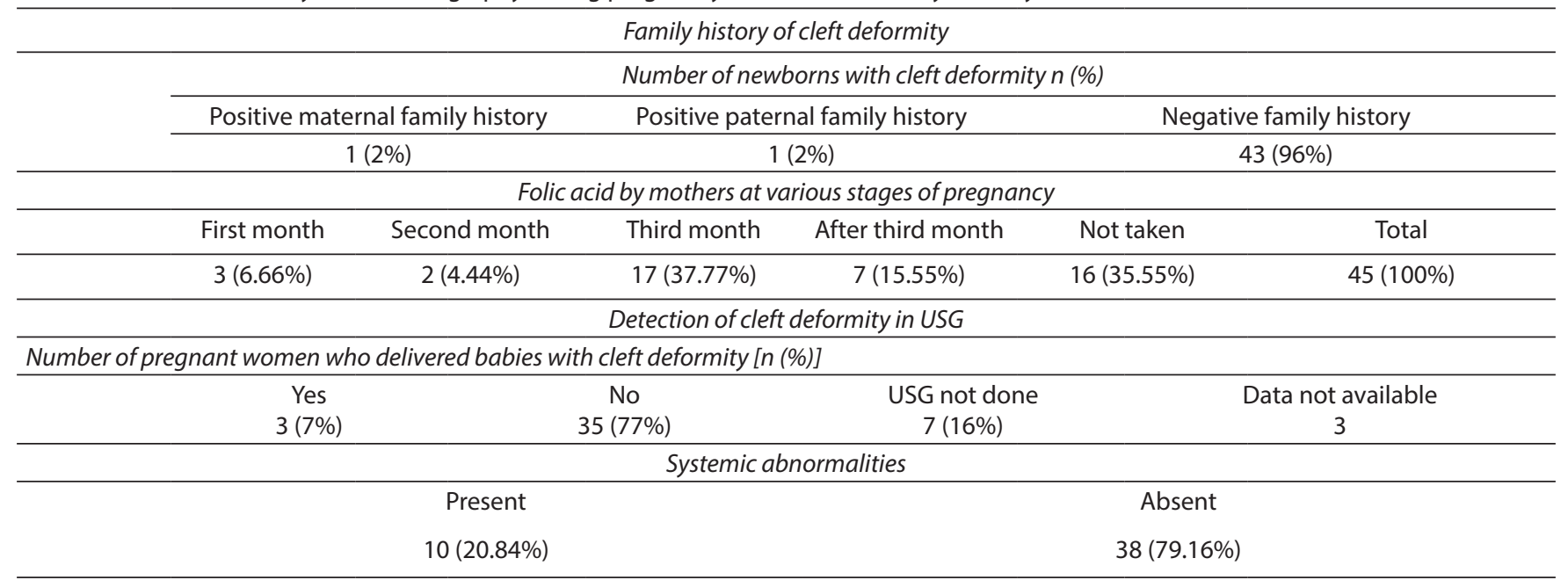

Table 3: Description of various systemic abnormalities with cleft type, gender, and laterality

\begin{tabular}{lccll}
\hline S. No. & Cleft deformity & Laterality & Sex & Systemic abnormality \\
\hline 1 & Group-1(A) & Left & $\mathrm{M}$ & Weak bones \\
2 & & $\mathrm{M}$ & Weak bones \\
3 & Group-2 & Bilateral & $\mathrm{F}$ & Hydrocephaly, multiple organomegaly \\
4 & Group-3 & Left & $\mathrm{F}$ & Down syndrome \\
5 & Group-2 & $\mathrm{M}$ & Ventricular septal defect \\
6 & Group-1 & $\mathrm{M}$ & Pierre Robin sequences, One foot deform- \\
& Group-2 & & $\mathrm{M}$ & ity, Ventricular septal defect \\
8 & Group-2 & Stickler syndrome \\
9 & Group-1(A), Group-1 & & $\mathrm{M}$ & Anophthalmus \\
10 & Group-2 & $\mathrm{F}$ & Pierre Robin sequences \\
\hline
\end{tabular}

Group-1- Isolated cleft lip, group-1 (A)-Cleft lip and alveolus, group-2- Isolated cleft palate, group-3- Cleft lip, alveolus and palate

of cleft deformities. CLP in the present study comprised of $29.16 \%$ of total orofacial cleft deformities comparable to the frequency of cleft lip and palate reported by Iregbulem ${ }^{48}$ in Nigeria (32\%) and Druschel et al. ${ }^{58}$ in New York (28.9\%) while most of the other studies found higher frequency of cleft lip and palate. $8,14,16,55,57,62-65$ Cleft of palate comprised of $27.08 \%$ of total orofacial cleft deformities in the present study similar to Jensen et al. ${ }^{8}$ in Denmark. While the distribution reported both higher ${ }^{14,47,55,57,60-62,64,65}$ and lesser frequency ${ }^{16,52,57,63,65}$ among other populations as compared to Chandigarh population. These differences in cleft type distribution in various populations may be due to difference in gene frequencies, a geographical clustering, differences in environmental factors, or methods of data collection as explained by Cooper et al. ${ }^{17}$

\section{Cleft Deformities According to Their Laterality}

The laterality of the cleft deformity in the present study was more on left side followed by right side and then bilateral, in agreement with the universal acceptance of left side predominance in cleft deformity. The results of many previous studies are similar to the results of current study. $5,7,8,14,16,35,38,53,54,56,62,67$ According to laterality of total $\mathrm{CL}$ cases in the present study, $50 \%$ of the clefts were on left side followed by right side (38.88\%) and bilateral (11.11\%) and the left: right: bilateral ratio was 1.31:1:0.29. Similar result was also reported by Elliott et al. ${ }^{60}$ in Zambia where they reported left: right bilateral ratio to be 1.14:1:0.30. The CLP was also predominant on left side. Among total cleft lip and palate cases, $42.85 \%$ were with cleft on left side followed by bilateral $35.71 \%$ and right side $21.42 \%$. The ratio of left: right: bilateral was 1.2:0.6:1 similar to Mestrovic et al. ${ }^{16}$ in Croatia who reported left: right: bilateral ratio of 1.67:0.6:1. Elliott et al. ${ }^{61}$ in Zambia found left: right: bilateral ratios as 0.95:1:1.10 contradictory to the present study. The predilection for the left side in unilateral clefts has been a recurrent finding in the literature related to oral clefts, and this seems to be a feature in all ethnic groups. No convincing explanation for these differences has been advanced, but a proposed explanation is that blood vessels, supplying the right side of the fetal head, leave the aortic arch closer to the heart and are perhaps better perfused by blood than those going to the left side as reported by Johnston et al. ${ }^{68}$

\section{Gender Wise Distribution of Cleft Deformities}

In the present study, CL deformity was more predominant in males as compared to females with the ratio of 8:1. This finding was in concordance to the results of many previous studi es. . $^{7,8,15,16,38,53,54,56,59,61,63,68,69}$ However, Tretsven ${ }^{70}$ reported equal distribution of $\mathrm{CL}$ among males and females, and few studies have also reported a predominance of $\mathrm{CL}$ among females. ${ }^{14,34,71}$ In the 
present study, bilateral cleft lip was present only in males and similar result were also reported by Stoll ${ }^{6}$ and Akker. ${ }^{72,73}$ However Rank et al. ${ }^{74}$ reported bilateral cleft lip only among females. Meskin et al. ${ }^{75}$ and Henriksson ${ }^{76}$ reported bilateral cleft lip more among females than among males. An equal distribution of CLP was found among males and females in the present study, which was different from many previous studies reported in the literature and majority of them were in favor of male predominance for CLP. ${ }^{7,8,14-16,35,38,55,57,58,61,64,74,76}$ Isolated cleft palate (CP) deformity in the present study was predominantly present in males as compared to females with the ratio of 1.6:1 similar to results of few studies. ${ }^{15,54}$ However, this finding was different from many previous studies, which reported higher frequency of $\mathrm{CP}$ among females than among males. ${ }^{3,5,7,8,12,14-16,35,51,57,62,64,68}$ Gregg et al. ${ }^{60}$ however found equal distribution of CP among males and females. Although $\mathrm{CP}$ was predominant in males in the present study but the chances of having this deformity was more among females as described in odds ratio. (Female odds ratio: 1.56) The difference in sex ratio with the other studies could be due to smaller sample of the present study. An explanation for the majority of clefts affecting the males more may be due to different threshold values in the two sexes; that is, more additive disposing factors are required for the manifestation of a cleft in females as compared to males. ${ }^{8}$ Tolarova and Cervenk $\mathrm{a}^{36}$ claimed that there is a threshold level, dependent on the sex of the proband, which means that girls need more polygens to express the anomaly. This hypothesis assumes that girls have a greater chance to transmit the defect to the next generation.

\section{Distribution of Newborns with Cleft Deformities According to Birth Order}

The history of birth order could be elicited for 45 babies from the mothers and maternal history of three babies was not possible as these babies had been abandoned by their parents. Among 45 children with various cleft deformities, 20 (44.44\%) were first in their birth order, 19 (42.22\%) were second, five (11.11\%) third, and one $(2.22 \%)$ was fourth in the birth order. Few studies ${ }^{38,51,70,77,78}$ have reported a positive association between increasing birth order and oral clefts while some studies ${ }^{79,80}$ reported no association between the two. However, in present study no attempt was made to determine an association between cleft deformities and birth order.

\section{Cleft Deformity and History of Folic Acid Intake by Mothers during Pregnancy}

In the present study, folic acid intake by mothers started when they first reported pregnancy to the doctor. Most of them reported at 3rd month of their pregnancy and only three mothers started folic acid at 1st month of pregnancy. Available data regarding the history of folic acid intake by mothers is not reliable because of recall bias by mothers after delivery. The current evidence with nutrition and OFC, however, remains equivocal, and it is still not clear (1) whether any effect is due to folic acid or other aspects of the multivitamin supplementation, (2) whether there is a therapeutic effect, dependent on vitamin or folic acid dosage, and (3) whether there is a genetic predisposition to OFC that can be explained in part by genetic polymorphisms in the foliate or multivitamin metabolic pathways. ${ }^{81,82}$ The protective role of folic acid would best be studied by prospective, randomized, clinical studies.

\section{Detection of Cleft Deformity in Ultrasonography during Pregnancy}

The present study revealed that 38 babies (out of 45 babies whose history was recorded) had USG at their intrauterine life. Out of these
38 babies with cleft deformity, a positive indication (detection) was there in only three cases. It appears that routine USG does not concentrate on OFC detection and there is a need for a special effort to detect the cleft deformity. A detailed examination of the fetal face may not occur routinely in the absence of risk factors, ${ }^{79-84}$ although most of the clefts deformities occur in patients with no known risk factors, ${ }^{83}$ prenatal cleft detection rate appeared to be higher when there are other developmental anomalies detected, compared with isolated clefts, ${ }^{85}$ possibly because a more detailed facial investigation was likely to be undertaken or when clefts were larger and more readily visualized. There is some evidence that suggested that improved training to radiologists and gynecologists could increase the detection rates of orofacial clefts during pregnancy. ${ }^{83}$ Alternative techniques, such as transvaginal sonography, are also worth considering in the detection of orofacial cleft. This later technique is not routinely used but is reported to allow earlier visualization of the face and better image resolution. ${ }^{84,85}$ Very high sensitivity (92-96\%) and specificity (100\%) for prenatal cleft detection have been reported, but this did not include isolated cleft palates. ${ }^{86} \mathrm{As}$ an unfortunate consequence of the diagnosis of a prenatal cleft, some families may choose to terminate the pregnancy, even in the absence of any other malformations. Others contend that because cleft is rarely life threatening and does not, by and large, involve mental impairment, termination should not usually be offered. ${ }^{87}$ In one parental survey, $47 \%$ chose a prenatal diagnosis but if positive would probably or definitely not consider termination. ${ }^{88}$ Facial clefts are often described as minor cosmetic malformations, but most parents of affected children perceive the defect as severe. Prenatal cleft diagnosis by ultrasound has been a possibility for some time, but the sensitivity has remained generally low. ${ }^{83}$ Advances in ultrasound technology, improvements in training and routine visualization of the fetal face are likely to be key in increasing the sensitivity of such an investigation. A positive advantage however, of detecting a cleft in USG is to prepare the parents for accepting the newborn with a cleft and provide counseling so as to minimize the trauma of the unexpected arrival of a baby with cleft.

\section{Cleft Deformity Associated with Other Systemic Abnormalities}

In the present study, 10 newborns out of 48 newborns with cleft deformity had congenital malformation. The overall percentage of subjects of cleft with associated major anomalies or syndromes was $22 \%$ in the present study. The results were in close agreement with that reported by other authors. ${ }^{49,58,83}$ Calzolari ${ }^{67}$ reported musculoskeletal anomalies were the most frequent associated defects (43.5\%) followed by $29.2 \%$ of central nervous system, $28.9 \%$ of the cardiovascular system, of which ventricular and atrial septal defects were the most common, followed by tetralogy of Fallot. Stoll and Roth ${ }^{83}$ reported, out of 406 newborns with cleft deformity, 118 were associated with 237 malformations other than cleft deformity, in these 10 had ventricular septal defect, 13 hydrocephaly, seven had clubfoot, eight had polydactyly, five had syndactyly, 20 had trisomy of either 13 or 18.

In the present study isolated cleft palate group comprised of $50 \%$ of associated malformation, similar to results of many previous studies. ${ }^{39,92,43}$ In the previous investigations, the frequency of other congenital defects ranged between 7.5 and $26.2 \% .^{55,89,90-93}$ In Denmark, approximately $10 \%$ of children with isolated cleft palate had the Pierre Robin triad as reported by Christensen et al..$^{55}$ while in the present study $23 \%$ of children with isolated cleft palate had Pierre Robin sequence. Stark ${ }^{84-93}$ found clubfoot to be the most 
common malformation. Shprintzen et al. ${ }^{94}$ reported an increased number of malformations in the head region, Lilius ${ }^{90}$ of extremity deformities, while Abyholm, ${ }^{43}$ malformations of central nervous system more frequently. Stoll et al. ${ }^{6}$ reported $8.8 \%$ of the infants, who had cardiovascular malformations defects, ventricular septal defects were the most frequent heart anomalies in the present study the total spectrum of other malformation could not be seen, because of the sample being limited in number. However, the associated malformations seen in the present study were Pierre Robin sequences, Stickler syndrome, Ventricular septal defect, multiple organomegaly, and Weak bones, Hydrocephaly, Microcephaly, Anophthalmus, and Down syndrome.

Future direction: Improved training to radiologists and gynecologists to sensitize them towards prenatal diagnosis of cleft lip and palate which may result in an increase in the detection rates of orofacial clefts during pregnancy. Possibilities could be explored to add one column in birth register to specify birth anomalies.

\section{Conclusion}

The incidence of cleft deformity in Chandigarh UT was found to be $0.97 / 1,000$ live births. The frequency of cleft deformity was more among males as compared to females except isolated cleft palate group which showed equal distribution. The laterality of the cleft deformity was more on left side followed by right side and then bilateral. The overall percentage of subjects of cleft with associated major anomalies or syndromes was $22 \%$. Out of these 38 babies with cleft deformity, a positive indication (detection) was there in only three cases.

Limitations of the study: The present study was done on the basis of records obtained from medical birth facilities. There could be some unnoticed patients with cleft lip and palate deformity which were born at their respective homes.

\section{Acknowledgement}

The Authors would like to extend their regards to The Registrar Birth and Death Registration Department, Chandigarh administration (Sector-17, Chandigarh UT).

\section{References}

1. Gorlin RJ, Cervenka J, Hannekam R: Syndromes of head and neck, 4th edition. New York, Oxford: Oxford University Press; 2001.

2. Tolarova MM, Mosby T, Pastor L, et al. Prevention of cleft lip and palate-the plan of today, the goal for the future. Paper no. 114, 2nd World Cleft Congress, Munich;2002 September 15-19.

3. Wyszynski DF. Cleft lip and palate: From origin to treatment. Oxford: Oxford University Press; 2002. p. 548.

4. Felix-Schollaert B, Prahl-Andersen B, Puyenbroek Jl, et al. De incidentie van cheilognathopalatoschisis in Nederland. Tijdschr Kindergeneeskd 1986;54(3):90-95.

5. Calzolari E, Milan M, Cavazzuti GB, et al. Epidemiological and genetic study of 200 cases of oral cleft in Emilia Romagna region of Northern Italy. Teratology 1988;38(6):559-564. DOI: 10.1002/tera.1420380603

6. Stoll C, Alembik Y, Dott B, et al. Epidemiological and genetic study in 207 cases of oral clefts in Alsace, north-eastern France. J Med Genet 1991;28(5):325-329. DOI: 10.1136/jmg.28.5.325

7. Fogh-Andersen P. Inheritance of hare lip and cleft palate. Copenhagen: Nyt Nordisk Forlag; 1942.

8. Jensen BL, Kreiborg S, Dahl E, et al. Cleft lip and palate in Denmark, 1976-1981: epidemiology, variability, and early somatic development. Cleft Palate J 1988;25(3):258-269.
9. Moller P. Cleft lip and palate. An epidemiologic and genetic study of cleft lip and palate in Iceland. Arch Oral Biol 1965;10:407-420.

10. Abyholm FE. Cleft lip and palate in Norway. Plast Reconstr Surg 1978;12(1):29-43. DOI: 10.3109/0284431780901047

11. Rintal A, Stegar T. Increasing incidence of clefts in Finland: reliability of hospital records and central register of congenital malformations. Scand J Plast Reconstr Surg 1982;16(1):35-40. DOI: 10.3109/02844318209006568

12. Hagberg C, Larson O, Milerad J. Incidence of cleft lip and palate and risk of additional malformations. Cleft Palate-Craniofac J 1997;35(1):40-45. DOI: 10.1597/1545-1569_1998_035_0040_ ioclap_2.3.co_2

13. Coupland MA, Coupland AI. Seasonality, incidence, and sex distribution of cleft lip and palate births in trent region, 1973-1982. Cleft Palate J 1988;25(1):33-37.

14. Singh $M$, Jawadi $M H$, Arya $L S$, et al. Congenital malformations at birth among live-born infants in Afghanistan - a prospective study. Ind J Pediat 1982; 49(398):331-335. DOI: 10.1007/BF02834416

15. Jakobsen PL. Occurrence of cleft lip and palate in Faroe islands and Greenland from 1950 to 1999. Cleft Palate-Craniofac J 2003;40(4): 426-430.DOI: 10.1597/1545-1569_2003_040_0426_ooclap_2.0.co_2

16. Mestrovic MM, Bagatin M. An epidemiological study of orofacial clefts in Croatia 1988-1998. J Cranio-Maxillofac Surg 2005;33(2):85-90. DOI: $10.1016 /$ j.jcms.2005.01.002

17. Cooper ME, Ratay JS, Marazita ML. Asian oral-facial cleft birth prevalence. Cleft Palate-Craniofac J 2006;43(5):580-589. DOI: $10.1597 / 05-167$

18. Singh M, Sharma NK. Spectrum of congenital malformation in newborn. Ind J Pediat 1980;47:239-244. DOI: 10.1007/BF02758201

19. Saifullah S, Chandra RK, Pathak IC, et al. Congenital malformation in newborn: a prospective longitudinal study. A preliminary report on 1000 consecutive births. Ind Pediat 1967;4(6):251-261.

20. Ghosh S, Bali L. Congenital malformations in the newborn. Ind J Child Health 1963;12:448-452.

21. Kolah PJ, Master PA, Sanghvi LD. Congenital malformations and perinatal mortality in Bombay. Am J Obs and Gynec 1967;97:400-406.

22. Aiyar RR, Agarwal JR. Observation in the Newborn: s study of 10,000 consecutive live births. Ind Pediat 1969;6(11):729-742.

23. Mital VK, Grewal RS. Congenital anomalies in neonates. Ind J Pediat 1969;36:356-365.

24. Gupta BM, Mathur HC, Sharda DC. A study of congenital malformations in central Rajasthan (Ajmer). Archives Child Health 1971;13:30-36.

25. Sharma B, Bajpai PC, Sharma NL. Some observations on congenital malformations. Ind J Pediat 1972;39(296):286-292. DOI: 10.1007/ BF02755419

26. Tibrewala NS, Pai PM. Congenital malformations in the newborn. Ind J Pediat 1974;11(6):403-407.

27. Reddy SG, Reddy RR, Bronkhorst EM, et al. Incidence of cleft lip and palate in the state of Andhra Pradesh, South India. Indian J Plast Surg 2010;43(2):184-9. DOI: 10.4103/0970-0358.73443

28. Goravalinagappa JP, Nashi HK. Congenital malformations in a study of 2398 consecutive births. Ind J Med Res 1979;69:140-146.

29. Kulshrestha R, Upadhaya P, Nath LM. Congenital malformations in live born infants in a rural community. Ind Pediat 1983;20(1):45-49.

30. Choudhury A, Talukder G, Sharma A. Neonatal congenital malformations in Calcutta. Ind Pediat 1984;21(5):399-407.

31. Choudhury AR, Mukherjee M, Sharma A, et al. Study of $1,26,266$ consecutive births for major congenital defects. Ind J Pediat 1989;56(4):493-499. DOI: 10.1007/BF02722422

32. Chaturvedi P, Banerjee KS. Spectrum of congenital malformations in the newborns from rural Maharashtra. Ind J Pediat 1989;56(4):501-507. DOI: 10.1007/BF02722424

33. Balakrishnan C. Indian classification of cleft lip and palate. Indian J Plast Surg 1975;8:23-24.

34. Kalle SM. History of Nagpur plastic, reconstructive and maxillofacial surgery unit: 1st plastic surgery department in India. Indian J Plastic Surg 2003;36(2):134-137. DOI: 10.1055/s-00042863 
35. Azaz B, Koyoumdjisky-Kaye E. Incidence of clefts in Israel. Cleft PalateCraniofac J 1967:4:227-233.

36. Tolarova MM, Cervenka J. Classification and birth prevalence of orofacial clefts. Am J Med Genet 1998;75(2):126-137.

37. Fraser FC. The genetics of cleft lip and cleft palate. Am J Hum Genet 1970;22:336-352.

38. McMahon B, McKeown T. The birth prevalence of harelip and palate related to birth rank and maternal age. Am J Hum Genet 1953;5(2):176-183.

39. Bonaiti C, Briard ML, Feingold J. An epidemiological and genetic study of facial clefting in France: epidemiology and frequency in relatives. J Med Genet 1982;19(1):8-15. DOI: 10.1136/jmg.19.1.8

40. Gregg T, Boyd D, Richardson A. The birth prevalence of cleft lip and palate in Northern Ireland from 1980-1990. Br J Orthod 1994;21(4):387-392. DOI: 10.1179/bjo.21.4.387

41. Kozelj V. Epidemiology of orofacial clefts in Slovenia, 19731993: comparison of the incidence in six European countries. J Craniomaxillofac Surg 1996;24(6):378-382. DOI: 10.1016/s10105182(96)80040-0

42. Czeizel AE. First 25 years of the Hungarian Congenital Abnormality Registry. Teratology 1997;55(5):299-305. DOI: 10.1002/(sici)10969926(199705)55:5<299:::aid-tera1>3.0.co;2-v

43. Gilmore SI, Hofman SM. Clefts in Wisconsin: incidence and related factors. Cleft Palate J 1966;3:186-199.

44. Niswander JD, Adams MS. Oral clefts in the American Indians. Public Health Rep 1967;82(9):807-812.

45. Lowry RB, Trimble BK. Incidence rates for cleft lip and palate in British Columbia 1952-71 for North American Indian, Japanese, Chinese and total populations: secular trends over twenty years. Teratology 1977;16(3):277-283. DOI: 10.1002/tera.1420160306

46. Fraser GR, Calnan JS. Cleft lip and palate: seasonal incidence, birth weight, birth rank, sex, site, associated malformations and parental age. Arch Dis Child 1961;36(188):420-423. DOI: 10.1136/adc.36.188.420

47. Altemus LA. The incidence of cleft lip and palate among North American Negroes. Cleft Palate J 1966;3:357-361.

48. Iregbulem LM. The incidence of cleft lip and palate in Nigeria. Cleft Palate J 1982;19(3):201-205.

49. Srivastava A, Bang RL. Facial clefting in Kuwait and England: a comparative study. Br J Plast Surg 1990;43(4):457-462. DOI: 10.1016/0007-1226(90)90013-p

50. Neel JV. A study of major congenital defects in Japanese infants. Am J Hum Genet 1958;10(4):398-445.

51. Koguchi H. Population data on cleft lip and cleft palate in the Japanese In Melnick M, Bixler D, Shields ED (eds): "Etiology of Cleft Lip and Cleft Palate," New York: A.R. Liss. 1980;297-323.

52. Saxen I, Lahti A. Cleft lip and palate in Finland: incidence, secular, seasonal, and geographical variations. Teratology 1973;9(2):217-224. DOI: 10.1002/tera.1420090213

53. Will AL, Parsons RW. Characteristics of new patients at Illinois cleft palate teams. Cleft palate-Craniofac J 1991;28(4):378-384. DOI: 10.1597/1545-1569_1991_028_0378_conpai_2.3.co_2

54. Murray JC, Hirsch SD, Buetow KH, et al. Clinical and epidemiologic studies of cleft lip and palate in the Philippines. Cleft PalateCraniofac J 1997;34(1):7-10.DOI: 10.1597/1545-1569_1997_034_0007_ caesoc 2.3.co 2

55. Taher AA. Cleft lip and palate in Tehran. Cleft Palate-Craniofac J 1992;29(1):15-16. DOI: 10.1597/1545-1569_1992_029_0015_ clapit_2.3.co_2

56. Menegotto BG, Salzano FM. Epidemiology of oral clefts in a large south America sample. Cleft Palate-Craniofac J 1991;28(4):371-377. DOI: 10.1597/1545-1569_1991_028_0373_eoocia_2.3.co_2

57. Omari FA, Omari IK. Cleft lip and palate in Jordan: birth prevalence rate. Cleft Palate-Craniofac J 2004;41(6):609-612. DOI: 10.1597/03-034.1

58. Druschel CM, Hughes JP, Olsen CL. First year of life mortality among infants with oral clefts: New York state, 1983-1990. Cleft Palate-Craniofac J 1996;33(5):400-405. DOI: 10.1597/15451569_1996_033_0400_fyolma_2.3.co_2
59. Vallino-Napoli LD, Riley MM, Halliday J. An epidemiologic study of isolated cleft lip, palate, or both in Victoria, Australia From 1983 to 2000. Cleft Palate-Craniofac J 2004;41(2):185-194. DOI: 10.1597/02-076

60. Gregg TA, Leonard AG, Hayden C, et al. Birth prevalence of cleft lip and palate in Northern Ireland (1981-2000). Cleft Palate-Craniofac J 2008;45(2):141-146. DOI: 10.1597/06-045.1

61. Elliott RF, Jovic $G$, Beveridge M. Seasonal variation and regional distribution of cleft lip and palate in Zambia. Cleft Palate Craniofac J 2008;45(5):533-538. DOI: 10.1597/07-086.1

62. Mcleod NM, Urioste ML, Saeed NR. Birth prevalence of cleft lip and palate in Sucre, Bolivia. Cleft Palate-Craniofac J 2004;41(2):195-198. DOI: 10.1597/02-116

63. Spirtz RA, Arnold TD, Buonocore S, et al. Distribution of orofacial clefts and frequent occurrence of an unusual cleft variant in the Rift valley of Kenya. Cleft Palate-Craniofac J 2007;44(4):374-377. DOI: 10.1597/06-136.1

64. Aljohar A, Ravichandran K, Subhani S. Pattern of cleft lip and palate in hospital based population in Saudi Arabia: retrospective study. Cleft Palate-Craniofac J 2008;45(6):592-596. DOI: 10.1597/06-246.1

65. Onyango JF, Noah S. Pattern of the clefts of the lip and palate managed over a three year period at a Nairobi hospital in Kenya. East Afr Med J 2005;82(12):649-651. DOI: 10.4314/eamj.v82i12.9371

66. Clark JD, Mossey PA, Sharp L, et al. Socioeconomic status and orofacial clefts in Scotland, 1989 to 1998. Cleft Palate Craniofac J 2003;40(5):481-485. DOI: 10.1597/1545-1569_2003_040_0481_ ssaoci_2.0.co_2

67. Calzolari E, Bianchi F, Rubini M, et al. Epidemiology of cleft palate in Europe: implications for genetic research. Cleft Palate-Craniofac $J$ 2004;41(3):244-249. DOI: 10.1597/02-074.1

68. Johnston MC, Bronsky PT. Prenatal craniofacial development, new insight on normal and abnormal mechanism. Crit Rev Oral Biol Med 1995;6(1):368-422. DOI: 10.1177/10454411950060010301

69. Tal Y, Dar H, Winter ST, et al. Frequency of cleft lip and palate in Northern Israel. Isr J Med Sci 1974;10:515-518.

70. Czeizel A, Tusnady G. An epidemiologic study of cleft lip with or without cleft palate and posterior cleft palate in Hungary. Hum Hered 1972;21(1):17-38. DOI: 10.1159/000152380

71. Trestven VE. Incidence of cleft lip and palate in Montana Indians. J Speech Hear Dis 1963;28:52. DOI: 10.1044/jshd.2801.52

72. Yi NN, Yeow VK, Lee ST. Epidemiology of cleft lip and palate in Singapore a 10 year hospital-based study. Ann Acad Med Singapore 1999;28(5):655-659.

73. Akker A, Hoeksma JB, Prahl Andersen B. Schisis in Nederland. De vraagnaarbehandeling van schisispatientenNed Tijdschr THK 1987;94(3):520-525.

74. Rank BK, Thomson JA. Cleft lip and palate in Tasmania. Med J Aust 1960;47(2):681-689.

75. Meskin LH, Pruzansky S, Gullen WH. An epidemiologic study of factors related to the extent of facial clefts. Cleft Palate J 1968;5:23-29. DOI: 10.1016/0002-9416(71)90192-8

76. Henriksson TG. Cleft Lip and Palate in Sweden. Uppsala: Institute for Medical Genetics of the University of Uppsala, Thesis; 1971.

77. Ingalls TH, Taube IE, Klingberg MA. Cleft lip and cleft palate: epidemiologic considerations. Plast Reconstr Surg 1964;34:1-10. DOI: 10.1097/00006534-196407000-00001

78. Hay S, Barbano H. Independent effects of maternal age and birth order on the incidence of selected congenital malformations. Teratology 1972;6(3):271-279 DOI: 10.1002/tera.1420060304

79. Robert E, Kallen B, Harris J. The epidemiology of orofacial clefts. 1. Some general epidemiological characteristics.J Craniofac Genet Dev Biol 1996;16(4):234-241.

80. Spry CC, Nugent MAC. Some epidemiological aspects of clefts of the primary and secondary palate in South Australia, 1949-1968. Aust Dent J 1975;20(4):250-256. DOI: 10.1111/J.1834-7819.1975.TB05056.X

81. Mulinare J, Erickson JD, James LM, et al. Does periconceptional use of multivitamins reduce the occurrence of birth defects? Am J Epidemiol 1995;41:3-4. 
82. Schorah CJ, Wild J. Fortified foods and folate intake in women of child-bearing age. Lancet 1993;341(10):1417-1419. DOI: 10.1016/01406736(93)90991-0

83. Stoll C, Dott B, Alembik Y, et al. Evaluation of prenatal diagnosis of cleft lip/ palate by fetal ultrasonographic examination. Ann Genet 2000;43(1):11-14. DOI: 10.1016/s0003-3995(00)00011-3

84. Grandjean $H$, Larroque $D$, Levi S. The performance of routine ultrasonographic screening of pregnancies in the Eurofetus study. Am J Obstet Gynecol 1999;181(2):446-454. DOI: 10.1016/s00029378(99)70577-6

85. Climenti M, Tenconi R, Bianchi F, et al. Evaluation of prenatal diagnosis of cleft lip with and without cleft palate and cleft palate by ultrasound: experience from 20 European registries. Prenat Diagn 2000;20(11):870-875.

86. Bronshtein M, Blumenfeld I, Blumenfeld Z. Early prenatal diagnosis of cleft lip and its potential impact on the number of babies with cleft lip. Br J Oral Maxillofac Surg 1996;34(6):486-487. DOI: 10.1016/ s0266-4356(96) $90241-7$

87. Sohan $\mathrm{K}$, Freer M, Mercer N, et al. Prenatal detection of facial clefts. Fetal Diagn Ther 2001;16(4):196-199. DOI: 10.1159/000053908
88. Johnson DD, Pretorius $\mathrm{DH}$, Budorick NE, et al. Fetal lip and primary palate: three-dimensional versus two-dimensional US. Radiology 2000;217(1):236-239. DOI: 10.1148/radiology.217.1.r00oc18236

89. Borker AS, Mathur AK, Mahaluxmivalas S. Epidemiology of facial clefts in the central province of Saudi Arabia. Br J Plast Surg 1993;46(8): 673-675. DOI: 10.1016/0007-1226(93)90198-k

90. Lilius DP. Clefts with associated anomalies and syndromes in Finland. Scand J Plast Reconstr Surg Hand Surg 1992;26(2):185-196. DOI: 10.3109/02844319209016011

91. Knox G, Braithwaite F. Cleft lips and palates in Northumberland and Durham. Arch Dis Child 1963;38(197):66-70. DOI: 10.1136/ adc.38.197.66

92. Stark R. Cleft Palate: a Multidiscipline Approach. New York: Harper \& Row; 1968.

93. Fogh-Andersen P. Epidemiology and etiology of clefts. In: Bergsma D, ed. Third Conference on the Clinical Delineation of Birth Defects. Baltimore: Williams and Wilkins 1971:50-53.

94. Shprintzen RJ, Siegel-Sadewitz VL, Amato J, et al. Anomalies associated with cleft lip, cleft palate, or both. Am J Med Genet 1985;20(4):585-595. DOI: 10.1002/ajmg.1320200404 